\title{
Federal government unveils patient-oriented research strategy
}

$\mathrm{T}$ he fruits of medical research are often absent in clinical settings, a problem the Canadian government plans to address with a national patient-oriented strategy to "better integrate health research and health care," federal Minister of Health Leona Aglukkaq vowed Monday.

"Today, a new patient-oriented research strategy is being launched that is designed to help provinces and territories meet the challenge of delivering high-quality, cost-effective health care by ensuring that the right patient receives the right treatment at the right time," Aglukkaq said during an address to delegates at the Canadian Medical Association's 144th annual general meeting in St. John's, Newfoundland and Labrador. "Evidence-based research will help health care providers compare the outcomes of different treatment options for patients and determine the best course of action.'

The gulf between the wet-bench and the bedside is a well-known problem in Canada, a country with strong basic medical research that too rarely results in actual benefits for patients (www.cmaj .ca/cgi/doi/10.1503/cmaj.109-3814).

Other countries have long since turned their attention to patient-oriented clinical trials and comparative health research. The United States, for example, created a Patient-Centered Outcomes Research Institute, which will receive some US\$200 million a year starting in 2013 to find the tests, treatments and protocols that produce the best results for patients (www.cmaj.ca /cgi/doi/10.1503/cmaj.109-3269), and a new National Institutes of Health institute to increase therapeutic innovation (www.cmaj.ca/cgi/doi/10.1503/cmaj .109-3777).

Canada's new strategy proposes to roll all manner of research, from clinical trials to comparative outcomes research, under the rubric of one umbrella. It defines patient-oriented research as

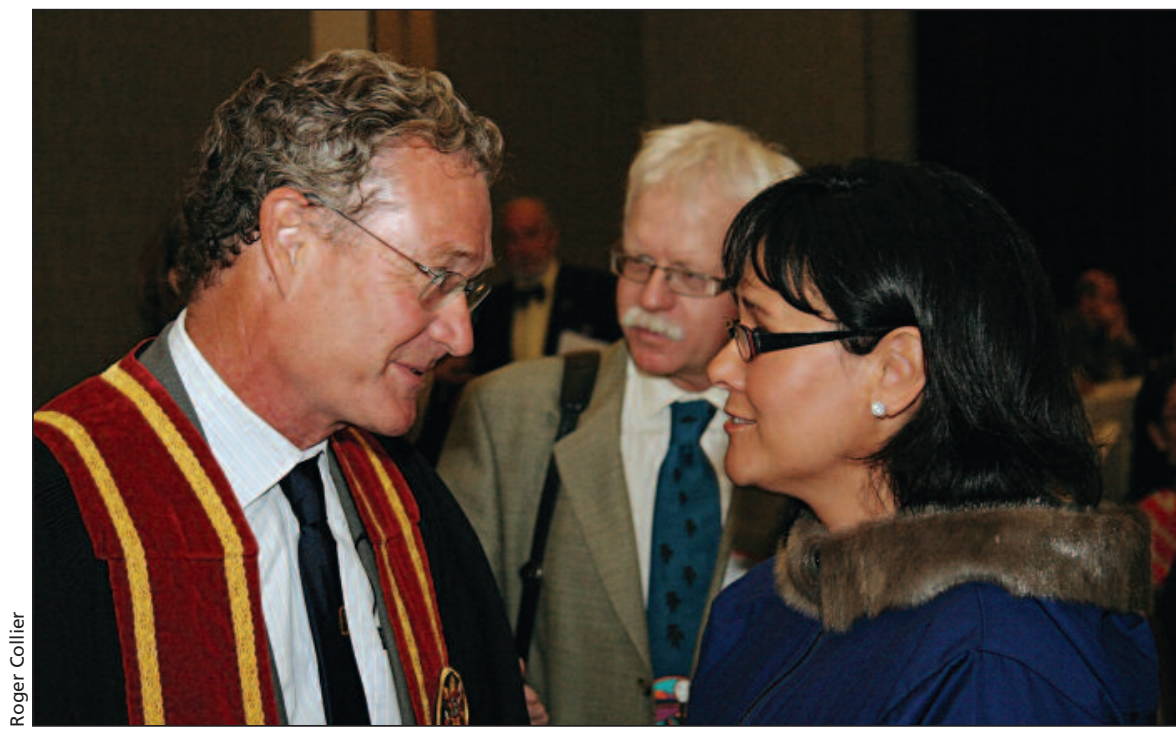

Federal Minister of Health Leona Aglukkaq meets with Canadian Medical Association President Dr. Jeff Turnbull at the association's 144th annual general meeting in St. John's, Newfoundland and Labrador.

"continuum of research, from initial studies in humans to comparative effectiveness and outcomes research, and the integration of this research into the health care system and clinical practice" (www.cihr-irsc.gc.ca/e/44000.html).

The strategy's main objectives?

- "To create a collaborative, panCanadian process for identifying, establishing and addressing patientoriented research priorities;

- To establish an integrated, leadingedge pan-Canadian clinical research infrastructure along the full continuum of patient-oriented research;

- To grow Canada's capacity to attract, train and mentor health care professionals and health researchers, as well as to create sustainable career paths in patient-oriented research;

- To strengthen organizational, regulatory and financial support for clinical studies in Canada and enhance patient and clinician engagement in these studies; and

- To improve processes for the early identification of best practices, expedite their development and harmo- nization into guidelines for patient care and support their adoption by clinicians, caregivers and patients."

"The Strategy aims at strengthening organizational, regulatory and financial support for clinical studies in Canada to improve translation of innovative diagnostic and therapeutic approaches to the bedside," Dr. Alain Beaudet, president of CIHR, said in a press release (www.cihr-irsc.gc.ca/e/44130.html). "It will bring together a vast coalition of clinical researchers and stakeholders to help the provinces and territories meet the challenge of delivering high quality, cost-effective health care.'

Implementation of the strategy will be monitored by a steering committee, whose membership will include CMA President Dr. Jeffrey Turnbull, who says the initiative will create clinical research infrastructure, improve patient recruitment and funding for clinical trials, and help Canada to attract and retain top medical researchers.

"It would be about, yes, better and more effective drugs, but it would also be about how knowledge changes policy." 
"How does the new knowledge that we generate change the way we practise medicine in different health care settings?" asks Turnbull. "It is the practical application of knowledge to transform the way we deliver care."

The remainder of Aglukkaq's speech contained few surprises. She reaffirmed the federal government's intention to renew the intergovernmental health accord upon its expiry in 2014 and to continue the annual $6 \%$ escalator for health transfer payments to provinces (www.cmaj.ca/cgi/doi/10.1503/cmaj .109-3865).

Aglukkaq said the federal government intends to pursue a single national health accord in 2014, not a hodgepodge of pacts with each province and territory. "There will be clear emphasis on accountability," she added. "This way, Canadians will be able to know that we are achieving real results in improving the system."

The absence of details on precisely what the federal government intends to do when the current health accord expires was unfortunate, says Dr. Robert
Woollard, a board member of Canadian Doctors for Medicare. "The most glaring hole is what is going to happen in 2014. It wasn't clear that she had a vision for the accord."

Canadian Doctors for Medicare called for the timely development of a new intergovernmental health accord, featuring a longer term (10 years) that allows for better planning. It should also reflect the needs of all regions in the country, honour the principles of the Canada Health Act and ensure all Canadians have fair and equitable access to health care regardless of their financial situations, the association says.

In her address, Aglukkaq also lauded federal initiatives to close the health services gap between First Nations and Inuit populations and the rest of Canada, to promote health and disease prevention, to develop a national mental health strategy, to attract more doctors and nurses to rural areas, to help prevent drug shortages and to continue national efforts to reduce cancer.

Woollard was unimpressed, calling Aglukkaq's address "a nice outline of generalities." The professor of family practice at the University of British Columbia in Vancouver added that "I didn't detect any serious commitments to action."

Dr. Sandra Luscombe, president of the Newfoundland and Labrador Medical Association, was encouraged that Aglukkaq appeared to want to engage the public and physicians, but felt the address was lacking in one important area. "I would have liked to see discussion on setting national health standards."

The federal government needs to take a leadership role in setting and meeting health goals in areas such as pharmacare, home care and long-term care, says the developmental pediatrician at the Janeway Children's Health and Rehabilitation Centre in St. John's.

The excuse that national standards are difficult to establish because health needs differ from province to province is a tired one, Luscombe adds. "We are more alike than we are different." Roger Collier, CMAJ

CMAJ 2011. DOI:10.1503/cmaj.109-3978 